Анна Мезенко

Учреждение образования «Витебский государственный

университет имени П.М. Машерова»

Филологический факультет

Кафедра общего и русского языкознания

tel.: +375212589673

e-mail: mezenka1@yandex.ru

ORCID ID: https://orcid.org/0000-0002-5192-767X

\title{
Особенности номинации аптек: семантическое зонирование
}

Ключевые слова: оним, ономастикон, товароним, прагматоним, семантическое зонирование.

Наименования аптек - один из наиболее быстро пополняемых разрядов онимной системы, элементы которого по ряду социальных и экономических причин до настоящего времени оставались за рамками всестороннего лингвистического анализа. Актуальность исследования этих единиц обусловлена прежде всего тем, что в них отражается (хотя и специфическим образом) окружающий мир, а также сам человек как часть этого мира, его ментальность. Именно поэтому комплексное изучение рассматриваемой онимной лексики будет способствовать решению глобальной задачи системного описания имен собственных с позиций антропоцентризма, формирующего новую научную парадигму современного языкознания.

Изучение названий аптек отдельных территорий, отражающих современные номинативные и языковые тенденции, имеет важное значение для выявления номинативных параллелей, языковых особенностей и общих закономерностей, но пока находится на начальной стадии и требует к себе более пристального внимания ономастов. Актуальность такого исследования объясняется также тем, что как в белорус- 
ской, так и в польской и русской ономастике названия аптек до сих пор не были самостоятельным предметом исследования. Изучение их особенностей только на уровне одного языка позволяет удовлетворительно описать конкретный ономастикон, но не позволяет установить законы ономастических систем. Выход за рамки одной языковой системы даст возможность увидеть в языковых формах единство и своеобразие ономастического мышления социума и его конкретно-языковое выражение.

Поскольку аптеки занимаются реализаций лекарств, которые в этом отношении в первую очередь выступают товаром, то и сами названия аптек иногда причисляют к товаронимам. Еще совсем недавно в ономастике не было единого подхода к определению места словесных товарных знаков среди разрядов онимов. С одной стороны, товарный знак - не оним (ранние работы А.В. Суперанской [Суперанская 2009, 211-213]); с другой, товарный знак - имя собственное однотипного множества предметов, серии, группы предметов, входящих в определенный класс [Соболева, Суперанская 1986].

Однако учитывая то, что названия аптек имеют денотаты в прагматической сфере деятельности человека, связанные с практикой, в том числе с оказанием фармацевтических услуг, они с полным на то основанием могут быть отнесены к такому разряду ономастической лексики,

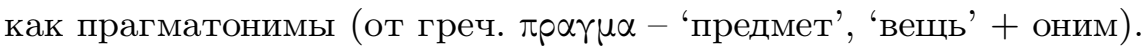

Под данным термином, получившим дефиницию в «Словаре русской ономастической терминологии» Н.В. Подольской, «пока условно, объединены различные категории имен собственных, имеющие денотаты в прагматической сфере деятельности человека, связанные с практикой, с предметной областью...» [Подольская 1988, 110]. Однако в ономастической литературе существуют и другие точки зрения как на само определение термина, так и на место названий аптек в онимной системе.

Цель исследования состоит в выявлении особенностей современной системы названий аптек в трёх сходных по величине и статусу городах Республики Беларусь, Республики Польша и Российской Федерации.

Материалом для работы послужили данные интернет-справочников: Адреса и телефоны аптек Витебска: gorodvitebsk.by/katalog/apteki и Аптеки в Смоленске, адреса и телефоны: http://orenvis.ru/, Аптеки в Быдгоще: www.pkt.pl/szukaj/apteki/bydgoszcz.

Использованы дескриптивный, сопоставительный, ареальный методы, элементы статистического анализа. 


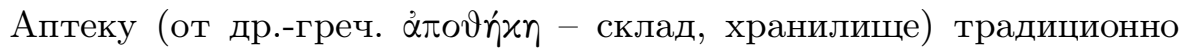
рассматривают как особую специализированную организацию системы здравоохранения, занимающуюся изготовлением, фасовкой, анализом и продажей лекарственных средств. С развитием постиндустриального общества все большую роль начинают играть функции, которые помогают преумножить капитал. Вероятно, этим объясняется интенсивное открытие аптек, приводящее к жесткой конкуренции в крупных городах. Все большее значение приобретают их названия: от номинаций зависят маркетинговые коммуникации, которые обусловливают экономическую эффективность продукции на рынке.

Названия аптек обладают рядом институциональных признаков, позволяющих дифференцировать их как единицы прагматонимного пространства среди других разрядов онимов. Главным среди них следует признать наличие в составе слов или составных именований, предназначенных для употребления в сфере здравоохранения.

Семантические группы этой лексики, участвующие в образовании наименований аптек, могут быть разделены на три зоны - «система», «лечение» и «здоровье».

Зона «система» включает 4 семантические группы: «порядок открытия», «местоположение», «предназначенность», «статус» (см. таблицу 1$)$.

\section{Таблица 1.}

Семантические группы названий аптек, входящих в зону «система»

\begin{tabular}{|c|c|c|c|c|}
\hline $\begin{array}{l}\text { № } \\
\Pi / \Pi\end{array}$ & $\begin{array}{c}\text { Семантическая } \\
\text { группа }\end{array}$ & Витебск & Быдгощ & Смоленск \\
\hline 1. & «порядок открытия» & 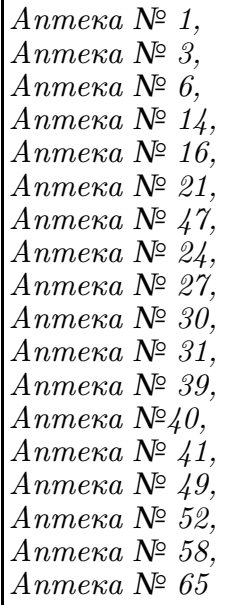 & $\begin{array}{l}\text { Alba II (см. при- } \\
\text { меч. 1), Alba III, } \\
\text { Alba IV, Alba V, } \\
\text { Alba VI, Alba VII }\end{array}$ & $\begin{array}{l}\text { Аптека № } 1 \text {, } \\
\text { Anтека № 086, } \\
\text { Anтека № 67, } \\
\text { Anтека № 002, } \\
\text { Anтека A-5, } \\
\text { Anтека № } 30\end{array}$ \\
\hline
\end{tabular}




\begin{tabular}{|c|c|c|c|c|}
\hline $\begin{array}{l}\text { № } \\
\text { П }\end{array}$ & $\begin{array}{c}\text { Семантическая } \\
\text { группа }\end{array}$ & Витебск & Быдгощ & Смоленск \\
\hline & & 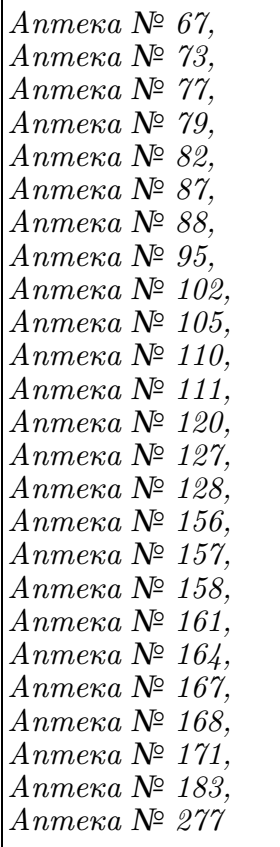 & & \\
\hline 2. & «местоположение» & $\begin{array}{l}\text { Дежурная аптека } \\
\text { № 127 на пр. Чер- } \\
\text { няховского, Ап- } \\
\text { тека на пр. Фрун- } \\
\text { зе, Аптека БЕЛ- } \\
\text { ФАРМ на Пуш- } \\
\text { кина, Аптека на } \\
\text { ул. Правдьь }\end{array}$ & $\begin{array}{l}\text { Apteka Toruńska, } \\
\text { Bielicka, Przy Ju- } \\
\text { rasza, Przy Kijow- } \\
\text { skiej, Przy Lesz- } \\
\text { czyñskiego, Przy } \\
\text { Sułkowskiego, Przy } \\
\text { Wojska Polskiego, } \\
\text { Bajka, Centralna, } \\
\text { Centrum, Gwiazda, } \\
\text { Na Jarach, Pary- } \\
\text { ska, Staromejska, } \\
\text { Akademicka, Pod } \\
\text { dębami, Pod lwem, } \\
\text { Pod tabędziem, } \\
\text { Polikliniczna }\end{array}$ & $\begin{array}{l}\text { Аптека на Лени- } \\
\text { на, Аптека Об- } \\
\text { ластной клини- } \\
\text { ческой больнииь, } \\
\text { ЗооВетЦентр, } \\
\text { Аптека Южнии }\end{array}$ \\
\hline 3. & «предназначенность» & $\begin{array}{l}\text { Моя аптека, Лю- } \\
\text { бимая аптека }\end{array}$ & $\begin{array}{l}\text { Twoja Apteka, Ap- } \\
\text { teka Rodzinna }\end{array}$ & $\begin{array}{l}\text { Anтека для вас, } \\
\text { Четьире лапьи, } \\
\text { Верньий друг }\end{array}$ \\
\hline 4. & «статус» & $\begin{array}{l}\text { Де Жур, Де- } \\
\text { журная аптека, } \\
\text { Аптека-дискаун- } \\
\text { тер }\end{array}$ & & $\begin{array}{l}\text { Смоленская со- } \\
\text { ииальная аптека, } \\
\text { Народная апте- } \\
\text { ка, Социальная } \\
\text { аптека }\end{array}$ \\
\hline
\end{tabular}


Данные таблицы свидетельствуют, что семантическая зона «система» включает номинации, указывающие на номер, адрес, предназначенность, статус.

Наибольшим количеством номинаций как в Витебске, так и в Смоленске представлена первая семантическая группа. Отдельные исследователи присвоение аптекам цифры в качестве идентификационного элемента связывают лишь с сохранением традиций советского времени [Томасик 2016, 372], хотя известно, что внутригородские названия, включающие в свой состав числительные, в Беларуси, в частности в Минске, Витебске, Могилеве, использовались еще в XIX в. Показательно, что в Смоленске значительно меньше названий такой модели. При этом в российском городе, помимо цифровой нумерации, используется и буквенная (ср.: Anтека $A-5)$.

Стоит отметить, что в американской урбанонимии, в частности в названиях линейных объектов, по данным Д. Стюарта, почти в половине городов функционировали и функционируют названия этой модели, нередко превышающие сотню, например, в Нью-Йорке или Чикаго [Stewart 1945, 248].

В предшествующие периоды истории данная модель широко применялась в бейрутской системе внутригородских названий улиц [Ланда 1969, 47].

Первоначальное их появление чаще всего было связано с быстрыми темпами застройки городов, особенно в послевоенный период, когда восстанавливались разрушенные во время войны населенные пункты. Номерные обозначения, как правило, являлись результатом воплощения в жизнь проектов новых микрорайонов. Кроме того, это самый экономный способ номинации объекта, позволяющий в то же время фиксировать очередность появления объектов.

Менее распространена в названиях аптек анализируемая семантическая группа - «порядок открытия» - в польском городе. Единицы данной группы используют в Быдгоще лишь отдельные владельцы аптек, фиксируя при этом последовательность открытия своих филиалов (Alba II, Alba III и др.).

Семантическая группа «местоположение» включает названия, содержащие в своем составе адрес учреждения, реже наименование района, в котором находится аптека, или другие учреждения, расположенные неподалеку. Сопоставление единиц данной группы показывает, что в белорусском городе задействованы преимущественно наименования, включающие названия линейного объекта, на котором находится аптека, иногда даже номер дома. Информацию же о районе или конкрет- 
ном учреждении, расположенном поблизости, фиксируют наименования смоленских учреждений здравоохранения.

Семантическая группа «предназначенность» представлена наименованиями, ориентированными на клиентов, дружеское отношение к ним, желаемые оценки, заботу о посетителях. При этом заметно отличие смоленских названий данной группы, репрезентирующих предназначенность их не только для оказания услуг по лечению людей, но и животных (ср.: аптека «Четьре лапь»», «Верный друг»).

Семантическую группу «статус» формируют названия, указывающие на статус учреждения. Сопоставляя витебские и смоленские названия, следует подчеркнуть, что у смолян заметно шире спектр статусов исследуемых онимов.

Зона «лечение» включает 4 семантические группы: «специалисты», «имена», «лекарства», «травы» (см. Таблицу 2).

\section{Таблица 2.}

Семантические группы названий аптек, входящих в зону «лечение»

\begin{tabular}{|c|c|c|c|c|}
\hline $\begin{array}{c}\text { № } \\
\Pi / \Pi\end{array}$ & $\begin{array}{c}\text { Семантическая } \\
\text { группа }\end{array}$ & Витебск & Быдгощ & Смоленск \\
\hline 1. & «специалисты» & Доктор Время & $\begin{array}{l}\text { Dr Zdrowie (Доктор } \\
\text { Здоровье) }\end{array}$ & $\begin{array}{l}\text { Аптекарь, } \\
\text { Знахарь, Лекарь, } \\
\text { Чудо-лекарь }\end{array}$ \\
\hline 2. & «имена» & Айболит & $\begin{array}{l}\text { Apteka im. Pasteura } \\
\text { (cм. примеч. 2), } \\
\text { Apteka im. Ojca } \\
\text { Pio (cм. примеч. 3), } \\
\text { Apteka im. Fleminga } \\
\text { (см. примеч. 4), } \\
\text { Apteka im. F. San- } \\
\text { gera (cм. примеч. 5) }\end{array}$ & $\begin{array}{l}\text { Авиченна, } \\
\text { Айболит, } \\
\text { Теремок, } \\
\text { Медея-Фарм }\end{array}$ \\
\hline 3. & «лекарства» & $\begin{array}{l}\text { Добрыля лекі, } \\
\text { Тәрралек }\end{array}$ & & \\
\hline 4. & «травы» & $\begin{array}{l}\text { Зялёная крама, } \\
\text { Зеленый лист, } \\
\text { Зелёная лавка, } \\
\text { Рамонак, } \\
\text { Эдельвейс Фарм, } \\
\text { Натур-Продукт }\end{array}$ & & $\begin{array}{l}\text { Ромашка, Паначея, } \\
\text { Крокус, Фауна }\end{array}$ \\
\hline
\end{tabular}

Семантическая группа «специалисты» состоит из единиц, содержащих в своем составе названия специалистов в области лекарств, а также лекарей, применяющих травы, заговоры, массирование, водолечение и другое в сочетании с различными ритуалами. Сопоставление еди- 
ниц данной группы показывает, что в белорусском городе задействовано только одно название, проприальная часть которого представляет собой словосочетание, опорным компонентом которого является "специалист с высшим медицинским образованием, имеющий право заниматься лечебно-профилактической деятельностью", с метафорическим созначением "время лечит". Наименования же смоленских учреждений здравоохранения фиксируют информацию о том, что смоляне в вопросах улучшения состояния доверяют не только специалистам в области лекарств, но и людям, связанным с медициной лишь частично.

Семантическую группу «имена» формируют названия, содержащие имена выдающихся врачей, персонажей литературных произведений, имевших отношение к медицине. Сопоставляя витебские и смоленские названия, следует подчеркнуть, что у смолян задействован более широкий спектр онимов.

Что касается третьей семантической группы, то из двух сопоставляемых городов она репрезентирована только в Витебске небольшим числом названий. Отсутствующие в смоленском ономастиконе наименования аптек этой группы находим в других русских городах, в частности в Астрахани (ср.: Аспирин, Таблетка [Томасик 2016, 371]).

Единицы, использующие названия растений с лечебными свойствами, востребованы как в белорусском, так и российском городе. При этом если смоляне из всего многообразия трав и шире растений по лечебным свойствам выделяют панацею, ромашку и крокус, то витебляне - травы и растения вообще (ср.: Зялёная крама, Зеленый лист, Зелёная лавка), почему-то эдельвейс и также ромашку.

Зона «здоровье» включает 3 семантические группы: «профессиональная отрасль», «пожелание», «эффект» (см. таблицу 1).

Данные таблицы свидетельствуют, что семантическая зона «здоровье» репрезентирована 3-мя группами номинаций, представляющими здоровье как профессиональную отрасль здравоохранения, пожелания и результат предпринятых усилий.

Семантическая группа «профессиональная отрасль» включает наименования, фиксирующие понимание здоровья, во-первых, как профессиональной функциональной подсистемы, важнейшей отрасли социально ориентированного рыночного хозяйства (ср.: Индустрия здоровья), во-вторых, как кода, программирующего наши клетки и сознание на правильное функционирование (ср.: Формула Жизни), в-третьих, как грань, призванную показывать его нарушения (ср.: Линия здоровья), в-четвертых, как ядро своеобразного поля, управляющее околоядерным пространством - физическим здоровьем, ближней периферией - 


\section{Таблица 3}

Семантические группы названий аптек, входящих в зону «здоровье»

\begin{tabular}{|c|c|c|c|c|}
\hline $\begin{array}{c}\text { № } \\
\text { П/П }\end{array}$ & $\begin{array}{c}\text { Семантическая } \\
\text { группа } \\
\end{array}$ & Витебск & Быдгощ & Смоленск \\
\hline 1. & $\begin{array}{l}\text { «профессиональ- } \\
\text { ная отрасль» }\end{array}$ & $\begin{array}{l}\text { Планета здоровья, } \\
\text { Формула Жизни } \\
\text { плюс, Аптека № } 5 \\
\text { Алена }\end{array}$ & $\begin{array}{l}\text { Apteka Dr. Max, } \\
\text { Dr. Pankowski } \\
\text { (см. примеч. 6), Ap- } \\
\text { teka im. prof. Ada- } \\
\text { manisa (см. при- } \\
\text { меч. 7), Apteka } \\
\text { Pharma im. Luka- } \\
\text { siewicza (см. при- } \\
\text { меч. 8) }\end{array}$ & $\begin{array}{l}\text { Здоровье плюс, Ин- } \\
\text { дстрия здоровья, } \\
\text { Линия здоровья, } \\
\text { Аптека Фарм Анна }\end{array}$ \\
\hline 2. & «пожелания» & & $\begin{array}{l}\text { DOZ (Dbam o zdro- } \\
\text { wie 'Заботимся } \\
\text { o здоровье'), Żyj } \\
\text { zdrowo (Живи } \\
\text { здоровьлм) }\end{array}$ & $\begin{array}{l}\text { Будь здоров, Здра- } \\
\text { вушка, На здоро- } \\
\text { вье, Здоровье от } \\
\text { nриродыс }\end{array}$ \\
\hline 3. & «эффект» & $\begin{array}{l}\text { 36, } 6 \\
\text { Рубикон }\end{array}$ & $\begin{array}{l}\text { Apteka z uśmiechem } \\
\text { (Anmeка с ульб- } \\
\text { кой), Nadzieja } \\
(\text { Надежда) }\end{array}$ & \\
\hline
\end{tabular}

умственным и психическим здоровьем, посылающим импульсы дальней периферии - социальному благополучию (ср.: Планета здоровья), в-пятых, к этой группе можно причислить также названия, включающие в свой состав имена владельцев торговых сетей аптек (ср.: Anmeка Фарм Анна).

В польском городе первую группу исследуемой зоны репрезентируют также названия, включающие в свой состав имена владельцев аптек, известных фармацевтов, деятельность которых способствовали совершенствованию фармацевтической отрасли.

Во вторую семантическую группу, российски и польско ориентированную и не нашедшую репрезентации в белорусском прагматонимиконе, вошли названия-пожелания, представляющие собой общеизвестные формы вежливости: Будь здоров! На здоровье! часть слогана Здравушка, за которой следует 100 лет без бед! А также польские Dbam о zdrowie (Заботимся о здоровье!), Żyj zdrowo (Живи здоровьм), причем первое из них в повседневном общении употребляется в трех вариантах: Dbam o zdrowie, DOZ [доз] и DOZ [дэозэт] [Томасик 2016, 371].

Наоборот, белорусски ориентированная и не имеющая репрезентации в исследуемом российском прагматонимиконе семантическая группа «эффект» включает цифровой индикатор нормальной температуры 
тела здорового человека (ср.: 36,6) и наименование Рубикон, широко известное благодаря выражению «перейти Рубикон», означающему 'пройти точку невозврата'. Еще одна семантическая группа «эффект», широко представленная в российских городах, только начинает формироваться в сопоставляемых ономастиконах. В настоящее время зарегистрировано только одно название в Витебске (Anтека 36,6).

Таким образом, обладая специфическим объектом номинации, наименования аптек характеризуются искусственным характером номинации и, как правило, прозрачностью мотивации. Семантические группы лексики, участвующие в образовании наименований аптек, четко подразделяются на три зоны - «система», «лечение» и «здоровье».

Несмотря на определенное различие в количестве аптек в сопоставляемых городах, наблюдается приблизительный паритет по семантическим группам зон, кроме отдельных отступлений. В частности, семантическая зона «система» характеризуется отсутствием в списке аптек польского города группы «статус», включающей в перечни белорусского и российского городов такие наименования, как Де Ж ур, Смоленская сочиальная аптека и подобные.

И в зоне «лечение» список названий исследуемых объектов польского города противополагается спискам белорусского и российского областных центров отсутствием групп названий «лекарства» и «травы», а также отличным наполнением семантической группы «имена». Если в Витебске и Смоленске в названиях аптек задействованы имена первого знаменитого врача, широко известного персонажа художественного произведения, то в Быдгоще - известных врачей-европейцев и прежде всего польских фармацевтов и владельцев аптек, в чем легко просматривается стремление поляков подчеркнуть значимость национального компонента и в этой области своего ономастикона.

Нельзя не заметить, что в семантической зоне «здоровье» в белорусском списке названий аптек отсутствует группа «пожелания» (в Быдгоще это $\dot{Z} y j$ zdrowo, DOZ, в Смоленске - Будь здоров, На здоровье, Здоровье от природы и др.), в содержательном смысле восполняемая наличием семантической группы «эффект» (ср.: 36,6; Рубикон, Nadzieja), отсутствующей в российском.

Из общих для названий аптек трех городов черт обращает внимание низкий процент использования латинских и греческих слов и морфем, характерных для медицинской лексики в целом. Наоборот, предпочтительное по отношению к другим семантическим группам обращение к единицам, связанным с наименованиями трав и растений, что неслучайно: мир трав и растений разносторонне отражается в сознании 
славян, сказывается на всей их жизни, в мифологическом творчестве и магически-ритуальной деятельности.

Как общее следует рассматривать и активное пополнение в последние десятилетия семантической группы «профессиональная отрасль» семантической зоны «здоровье» в трех сопоставляемых городах, поскольку в XXI в. здравоохранение все чаще рассматривается в качестве системообразующего фактора индустрии здоровья, понимаемой как синтез рыночных и нерыночных отношений, соотношение коммерческой и некоммерческой медицины.

\section{Литература}

Landa R.G. 1969, U arabov Azii: Putevye zametki, Moskva. [Ланда Р.Г. 1969, У арабов Азии: Путевые заметки, Москва.]

Podol'skaâ N.V., 1988, Slovar' russkoj onomastičeskoj terminologii, Moskva. [Пoдольская Н.В., 1988, Словарь русской ономастической терминологии, Москва.]

Soboleva T.A., Superanskaâ A.V., 1986, Tovarnye znaki, Moskva. [Соболева T.A., Суперанская А.В., 1986, Товарные знаки, Москва.]

Superanskaâ A.V., 2009, Obŝâa teoriâ imeni sobstvennogo, Moskva. [Суперанская А.В., 2009, Общая теория имени собственного, Москва.]

Tomasik S., 2016, Motivacionnye aspekty v nazvaniâh aptek gorodov Astrahani i Bydgoŝa, [v:] Onomastika Povolž'â: materialy XV Meždunar. nauč. konf. (Arzamas, 13-15 sentâbrâ 2016 g.), Arzamas - Sarov, s. 370-373. [Томасик С., 2016, Мотивачионнье аспекты в названиях аптек городов Acmрахани и Быдгоща, [в:] Ономастика Поволжья: материаль XV Междунар. науч. конф. (Арзамас, 13-15 сентября 2016 г.), Арзамас - Саров, c. $370-373$.

Stewart D.P., 1945, Names on the Land, New-York.

\section{Источники}

1. Адреса и телефоны аптек Витебска: gorodvitebsk.by/katalog/apteki

2. Аптеки в Смоленске, адреса и телефоны: http://orenvis.ru

3. Аптеки в Быдгоще: www.pkt.pl/szukaj/apteki/bydgoszcz

\section{Примечания}

1. Alba-от лат. албус 'белый'. 
2. Apteka im. Pasteura - Луи Пастер - французский микробиолог и химик, член Французской академии. Пастер, показав микробиологическую сущность брожения и многих болезней человека, стал одним из основоположников микробиологии и иммунологии.

3. Apteka im. Ojca Pio - Пио из Пьетрельчины, широко известный как Па́дре Пи́о - священник и монах итальянского происхождения из ордена капуцинов, прославлен как католический святой. Знаменит стигматами и совершением чудес. Канонизирован 16 июня 2002 года папой Иоанном Павлом II.

4. Apteka im. Fleminga - сэр Алекса́ндр Фле́минг (англ. Sir Alexander Fleming) - британский бактериолог, первооткрыватель пенициллина.

5. Apteka im. F. Sangera- Фредерик Сенгер - английский биохимик, один из четырех человек, получивших сразу две Нобелевские премии, разработавший структуры белков и ДНК.

6. Dr. Pankowski - Панковски - фамилия владельца аптеки.

7. Apteka im. prof. Adamanisa - польский фармацевт, занимающийся изучением химии лекарственных препаратов [Томасик, с. 371].

8. Apteka Pharma im. Lukasiewicza - польский фармацевт, химик-технолог и предприниматель. Изобрел керосиновую лампу [Томасик, с. 371].

\section{FEATURES OF THE NOMINATION OF PHARMACIES: SEMANTIC ZONING}

S U M M A R Y

The report considers the features of the pharmacy nomination in three cities of similar size and status in Belarus, Poland and Russia - Vitebsk, Bydgoszcz and Smolensk; semantic zones of vocabulary participating in formation of names of pharmacies - "system", "treatment" and "health" are revealed; the groups of names forming these semantic zones are established (in the zone I: the order of discovery, location, purpose, status, in zone II: experts, names, medicines, herbs, in zone III: the professional branch, desire, effect) and the specifics of their use. It is emphasized that the analysis of this category of onyms will contribute to the creation of a more complete onym picture of each of the regions, will allow to reveal both general and specific nominative and cultural features of the compared onomasticons. 